\title{
Carbon nanotube biosensors: The critical role of the reference electrode
}

\author{
Ethan D. Minot, ${ }^{\text {a) }}$ Anne M. Janssens, and Iddo Heller \\ Kavli Institute of Nanoscience, Delft University of Technology, 2628 CJ Delft, The Netherlands \\ Hendrik A. Heering \\ Leiden Institute of Chemistry, Leiden University, Einsteinweg 55, 2333 CC Leiden, The Netherlands \\ and Kavli Institute of Nanoscience, Delft University of Technology, 2628 CJ Delft, The Netherlands \\ Cees Dekker and Serge G. Lemay \\ Kavli Institute of Nanoscience, Delft University of Technology, 2628 CJ Delft, The Netherlands
}

(Received 30 May 2007; accepted 1 August 2007; published online 28 August 2007)

\begin{abstract}
Carbon nanotube transistors show tremendous potential for electronic detection of biomolecules in solution. However, the nature and magnitude of the sensing signal upon molecular adsorption have so far remained controversial. Here, the authors show that the choice of the reference electrode is critical and resolves much of the previous controversy. The authors eliminate artifacts related to the reference electrode by using a well-defined reference electrode to accurately control the solution potential. Upon addition of bovine serum albumin proteins, the authors measure a transistor threshold shift of $-15 \mathrm{mV}$ which can be unambiguously attributed to the adsorption of biomolecules in the vicinity of the nanotube. (C) 2007 American Institute of Physics. [DOI: 10.1063/1.2775090]
\end{abstract}

Biosensors based on nanoscale field-effect transistors have the potential to significantly impact drug discovery, disease screening, biohazard screening, and fundamental science. ${ }^{1}$ The adsorption of biomolecules on the sidewall of a semiconducting carbon nanotube (CNT) or nanowire causes changes in local electrostatic environment, thereby changing the conductance of the nanomaterial. Pioneering work has indicated that this modulation of conductivity can be utilized to build CNT-based ${ }^{2-11}$ and nanowire-based ${ }^{1,12}$ sensors for real-time electrical detection of proteins or DNA. These sensors must be carefully designed to give reliable measurements of biomolecule binding. Of critical importance is the electrostatic potential of the solution which strongly affects the conductivity of the nanomaterial. The solution potential was not well controlled in many CNT biomolecule-binding experiments. $^{3-10}$ Reported conductance changes can have little or no relationship to interactions between biomolecules and the CNT transistor, leading to unreliable sensors and hindering efforts to determine sensing mechanisms. We show that a major biosensing artifact can be removed by using a well-defined reference electrode to accurately control the solution potential.

Carbon nanotube biosensors are generally constructed as shown in Fig. 1(a). ${ }^{3-10}$ The device is exposed to solution, allowing protein adsorption on the semiconducting CNT. A metal wire is used to control the electrostatic potential of the solution. A gate voltage $V_{g}$, applied to the metal wire, can tune the conductance of the CNT, while a small bias $e V_{\text {bias }}<k_{B} T$ is used to monitor the CNT conductance [for example, see Fig. 1(b), curve 1]. The electrostatic potential difference between the solution and the CNT is determined by the applied gate voltage $V_{g}$ and the interface potential at the metal-liquid interface $V_{\text {interface }}$. This interface potential depends sensitively on electrochemical reactions occurring at the metal-liquid interface. Larrimore et al. have recently tested CNT sensors in solutions where this electrochemistry was controlled using a high concentration of a potential-

${ }^{\text {a)}}$ Electronic mail: minote@science.oregonstate.edu determining redox couple. ${ }^{13}$ Sensors for biomolecule binding are generally operated in buffer solutions where the redox species are not controlled and the background redox reactions are slow. In these conditions, $V_{\text {interface }}$ is unstable and unpredictable. In particular, we show that the voltage drop over the interface from the $\mathrm{Pt}$ electrode to the solution is sensitively perturbed by adding protein to the solution. The resulting shift in $V_{\text {interface }}$ can easily obscure the true signal from a CNT biosensor. To achieve artifact-free measurements, we utilize a $\mathrm{Ag} / \mathrm{AgCl}$ reference electrode which is commonly employed in electrochemistry instrumentation. The metal-solution interface of the $\mathrm{Ag} / \mathrm{AgCl}$ reference electrode is separated from the analyte solution by a porous glass frit. The frit prevents large molecules from reaching the metal surface and ensures that the redox conditions at the metal-liquid interface are well controlled.

Carbon nanotubes for our biosensors were grown on degenerately doped Si wafers with a $200 \mathrm{~nm}$ thick thermally grown oxide layer using patterned catalyst and chemical vapor deposition. ${ }^{14}$ Electrical contact to individual CNTs was made by metal electrodes $(\mathrm{Cr} / \mathrm{Au}, 1.5 / 30 \mathrm{~nm})$ on top of the CNT. After processing, the devices were imaged by atomic force microscopy (AFM) to measure tube length and diameter. Measurements reported here are from a $13 \mu \mathrm{m}$ long NT with diameter of $3 \mathrm{~nm}$. The effects that we report were confirmed by cleaning and reusing the CNT (1 min in fuming nitric acid removes all protein without damaging the CNT) and reproduced using a second device. A homebuilt flow cell was used to control the liquid environment of the CNT. Electrical contact to the liquid could be made using $\mathrm{Pt}$ wire, a $\mathrm{Ag} / \mathrm{AgCl}$ reference electrode, or both. The $\mathrm{Ag} / \mathrm{AgCl}$ reference electrode is a $\mathrm{Ag} / \mathrm{AgCl}$ wire immersed in $3 \mathrm{M} \mathrm{NaCl}$ solution, separated from the analyte solution by a porous Vycor glass plug (Bioanalytical Systems). The buffer solution for all measurements was phosphate-buffered saline (10 mM phosphate buffer $p \mathrm{H} 7.4,2.7 \mathrm{mM} \mathrm{KCl}$, and $137 \mathrm{mM} \mathrm{NaCl}$ ) and the protein solution is $10 \mu \mathrm{M}$ bovine serum albumin (BSA) (Sigma) in phosphate-buffered saline. 

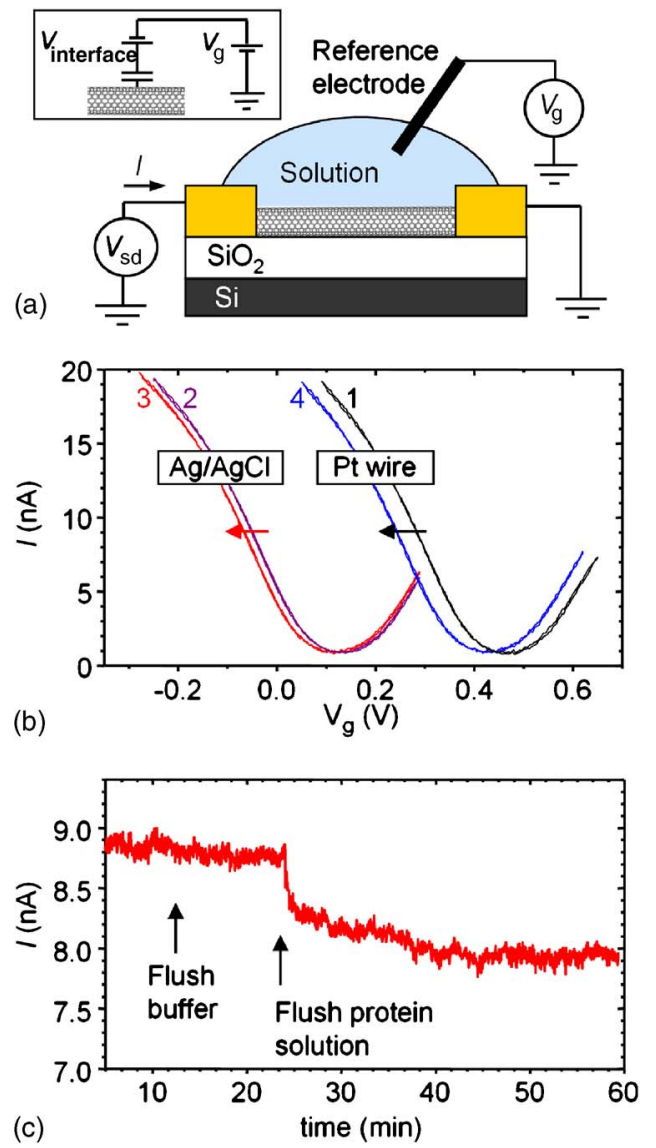

FIG. 1. (Color online) Carbon nanotube biosensor operated using different reference electrodes. (a) Schematic of a CNT biosensor. Inset: circuit model showing the capacitive coupling between the CNT and the solution, and the two voltage sources which set the solution potential. (b) Measurements of a CNT biosensor with $V_{\mathrm{sd}}=10 \mathrm{mV}$. The solution potential was controlled with either Pt wire or a $\mathrm{Ag} / \mathrm{AgCl}$ reference electrode. Curves 1 and 2 are measured in buffer solution (phosphate-buffered saline). Curves 3 and 4 are measured after 60 min incubation in protein solution $(10 \mu \mathrm{M}$ BSA in phosphate-buffered saline). A small electrochemical leakage current between the solution and the wires contacting the CNT $(<1 \mathrm{nA}$ measured at the reference electrode) has been subtracted. The Pt wire was pretreated with a 5 min sonication in acetone followed by butane flame annealing to white hot temperature. (c) Real-time detection of protein binding. The solution is held at a fixed potential by the $\mathrm{Ag} / \mathrm{AgCl}$ reference electrode with $V_{g}=-50 \mathrm{mV}$. The drop in current from 8.8 to $7.9 \mathrm{nA}$ corresponds to the $-15 \mathrm{mV}$ shift seen in (b). The time scale for the change in current corresponds to the typical time scale for protein adsorption on glass (Ref. 18).

Figure 1(b) shows $I-V_{g}$ measurements on the CNT biosensor before and after protein adsorption. The shape of the curves and the minimum conductance are characteristic of a semiconducting CNT at room temperature with a band gap of about $0.3 \mathrm{eV}$. Different reference electrodes, either Pt wire or a $\mathrm{Ag} / \mathrm{AgCl}$ reference electrode, were used to apply $V_{g}$. Curves 1 and 2 are taken before the addition of protein and curves 3 and 4 were measured after 60 min exposure to protein solution. When Pt wire was used to control the device (curves 1 and 4), the offset caused by the addition of protein was $-40 \mathrm{mV}$. When the $\mathrm{Ag} / \mathrm{AgCl}$ reference electrode was used to control the device, the offset was $-15 \mathrm{mV}$. The time dependence of the sensing effect is shown by a real-time measurement of conductance [Fig. 1(c)]. For the real-time measurement, the solution was held at a fixed electrostatic potential by the $\mathrm{Ag} / \mathrm{AgCl}$ reference electrode. Before and after all experiments, the $\mathrm{Ag} / \mathrm{AgCl}$ reference electrode was measured with respect to an identical control electrode to Downloaded 10 Aug 2010 to 131.180.130.114. Redistribution subje
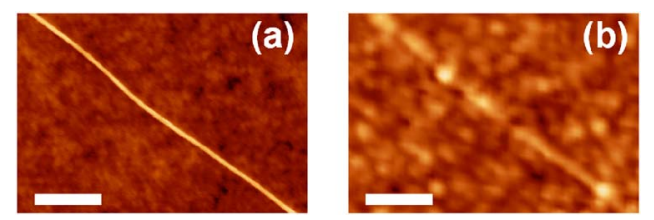

FIG. 2. (Color online) Nonspecific adsorption of BSA protein on a CNT and silicon oxide surface. (a) Before exposure to protein. (b) After 60 min incubation in protein solution (10 $\mu \mathrm{M}$ BSA in phosphate-buffered saline). In both images, the height scale is $3.5 \mathrm{~nm}$ and scale bars are $100 \mathrm{~nm}$.

ensure that $V_{\text {interface }}(\mathrm{Ag} / \mathrm{AgCl}$, solution) is stable within $\pm 1 \mathrm{mV}$. Protein adsorption on the CNT and oxide surface was confirmed by AFM imaging (Fig. 2).

The curves in Fig. 1(b) demonstrate the importance of $V_{\text {interface }}$ on the biosensor operation. Before protein adsorption, the Pt wire sets the solution potential about $300 \mathrm{mV}$ lower than the $\mathrm{Ag} / \mathrm{AgCl}$ reference electrode. This difference is due to the different liquid-metal interfaces and different surface electrochemistries. ${ }^{15}$ The two methods for controlling the solution potential ( $\mathrm{Pt}$ wire or $\mathrm{Ag} / \mathrm{AgCl}$ reference electrode) also give markedly different results for protein detection: curves 2 and 3 are offset by $-15 \mathrm{mV}$, while curves 1 and 4 are offset by $-40 \mathrm{mV}$. The different results for protein detection suggest that an artifact occurs when using Pt wire which can be explained as follows. The offset measured using the $\mathrm{Ag} / \mathrm{AgCl}$ reference electrode is due to proteins adsorbing on the CNT and on the oxide surface near the CNT. The adsorbed proteins shift the transistor threshold voltage by $-15 \mathrm{mV}$. A different offset is measured using Pt wire because protein also interacts with the Pt wire surface and changes $V_{\text {interface. }}$. Our measurements suggest that the $40 \mathrm{mV}$ offset between curves 1 and 4 is a combination of a $25 \mathrm{mV}$ change in $V_{\text {interface }}(\mathrm{Pt}$, solution) and the $15 \mathrm{mV}$ shift in transistor threshold caused by protein adsorption in the vicinity of the CNT.

To confirm the protein sensitivity of $V_{\text {interface }}$ for bare $\mathrm{Pt}$ wire in solution, we have also measured changes in this interface potential directly. Figure 3 shows the open-circuit potential $V_{\mathrm{oc}}$ of the Pt-solution interface in series with a $\mathrm{Ag} / \mathrm{AgCl}$ reference electrode interface. Measurements were made using a Keithley 6413 electrometer with input impedance $>10^{15} \Omega$. Because $V_{\text {interface }}$ of the $\mathrm{Ag} / \mathrm{AgCl}$ reference electrode is stable within $1 \mathrm{mV}$, the open-circuit voltage reflects changes at the Pt-solution interface. Figure 3 shows that (i) $V_{\text {interface }}\left(\mathrm{Pt}\right.$, solution) is sensitive to fluid flow as $V_{\text {oc }}$ has a transient drop when buffer is flushed and (ii) $V_{\text {interface }}(\mathrm{Pt}$, solution) drops by about $40 \mathrm{mV}$ after incubation with BSA protein. We have repeated this direct measurement of the protein sensitivity multiple times. The overall change

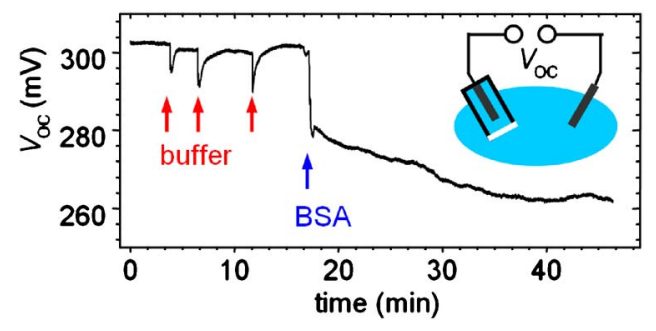

FIG. 3. (Color online) Open-circuit voltage of a $\mathrm{Ag} / \mathrm{AgCl}$ reference electrode in series with a bare Pt wire. The buffer solution and BSA protein solution are the same as used in Fig. 1.

to AIP license or copyright; see http://apl.aip.org/apl/copyright.jsp 
in $V_{\text {interface }}(\mathrm{Pt}$, solution) varies from about -20 to $-40 \mathrm{mV}$.

Our measurements imply that the results from earlier CNT biomolecule-binding sensors which used bare wire to control the solution potential ${ }^{3-10}$ are ambiguous. The interaction of protein with a Pt wire surface changes the electrostatic potential of the solution and can therefore cause changes in CNT conductivity. The artifacts associated with the use of a bare-metal wire as the reference must be eliminated before a "true" detection signal can be measured. Our measurements with a $\mathrm{Ag} / \mathrm{AgCl}$ reference electrode [Figs. 1(b) and 1(c)] show that a signal, although smaller, does remain when artifacts are eliminated. The $-15 \mathrm{mV}$ shift was reproduced within $1 \mathrm{mV}$ after cleaning and reusing the device. A second device with a $2 \mu \mathrm{m}$ long CNT and larger band gap gave a $-10 \pm 1 \mathrm{mV}$ shift upon addition of BSA. Understanding the magnitude of the biosensing signal as well as device-to-device differences is an important direction for future work.

The $\mathrm{Ag} / \mathrm{AgCl}$ reference electrode measurements [Figs. 1(b) and 1(c)] clarify previous controversy regarding sensing mechanisms. Chen et $a .^{4}$ considered two mechanisms to account for the reduction of $p$-type conductance when BSA adsorbs on a CNT transistor: (i) doping of the CNT by a layer of charged protein and (ii) decreased transparency of the metal-CNT Schottky barriers ${ }^{16}$ for $p$-type conduction due to changes in the CNT-metal work function difference (equivalent to increased transparency of the Schottky barriers for $n$-type conduction). Chen et al. argued that the work function difference mechanism is the dominant mechanism for sensing BSA and several other proteins, while doping due to adsorption of these proteins does not have an observable effect on CNT conductance. Using a $\mathrm{Ag} / \mathrm{AgCl}$ reference electrode instead of a Pt wire, however, we have observed a $-15 \mathrm{mV}$ threshold shift upon BSA adsorption [Fig. 1(b)], and a negligible change in the ratio of hole conduction to electron conduction. These results clearly support a bulk doping mechanism. ${ }^{5,17}$ We conclude that doping due to protein adsorption is significant, and can dominate over the work function difference mechanism.

We have shown that the performance of CNT biosensors depends critically on the control of solution potential. By operating $\mathrm{CNT}$ biosensors with a $\mathrm{Ag} / \mathrm{AgCl}$ reference electrode, we have obtained artifact-free measurements of the real-time electrical response to protein binding. These measurements help clarify the mechanisms for the electrical detection of proteins in solution by CNT biosensors. The importance of the reference electrode for CNT biosensor design, as demonstrated here, extends to a range of biological applications for nanoscale transistors.

This work was supported by the Netherlands Organization for Scientific Research (NWO) and NanoNed.

${ }^{1}$ Y. Cui, Q. Q. Wei, H. K. Park, and C. M. Lieber, Science 293, 1289 (2001).

${ }^{2}$ K. Besteman, J. O. Lee, F. G. M. Wiertz, H. A. Heering, and C. Dekker, Nano Lett. 3, 727 (2003).

${ }^{3}$ R. J. Chen, S. Bangsaruntip, K. A. Drouvalakis, N. W. S. Kam, M. Shim, Y. M. Li, W. Kim, P. J. Utz, and H. J. Dai, Proc. Natl. Acad. Sci. U.S.A. 100, 4984 (2003).

${ }^{4}$ R. J. Chen, H. C. Choi, S. Bangsaruntip, E. Yenilmez, X. W. Tang, Q. Wang, Y. L. Chang, and H. J. Dai, J. Am. Chem. Soc. 126, 1563 (2004).

${ }^{5}$ K. Bradley, M. Briman, A. Star, and G. Gruner, Nano Lett. 4, 253 (2004).

${ }^{6}$ A. Kojima, C. K. Hyon, T. Kamimura, M. Maeda, and K. Matsumoto, Jpn. J. Appl. Phys., Part 1 44, 1596 (2005).

${ }^{7}$ H. M. So, K. Won, Y. H. Kim, B. K. Kim, B. H. Ryu, P. S. Na, H. Kim, and J. O. Lee, J. Am. Chem. Soc. 127, 11906 (2005).

${ }^{8}$ H. R. Byon and H. C. Choi, J. Am. Chem. Soc. 128, 2188 (2006).

${ }^{9}$ D. W. Park, Y. H. Kim, B. S. Kim, H. M. So, K. Won, J. O. Lee, K. J. Kong, and H. Chang, J. Nanosci. Nanotechnol. 6, 3499 (2006).

${ }^{10}$ X. W. Tang, S. Bansaruntip, N. Nakayama, E. Yenilmez, Y. L. Chang, and Q. Wang, Nano Lett. 6, 1632 (2006)

${ }^{11}$ K. Maehashi, T. Katsura, K. Kerman, Y. Takamura, K. Matsumoto, and E. Tamiya, Anal. Chem. 79, 782 (2007).

${ }^{12}$ F. Patolsky and C. M. Lieber, Mater. Today 8(4), 20 (2005).

${ }^{13}$ L. Larrimore, S. Nad, X. J. Zhou, H. Abruna, and P. L. McEuen, Nano Lett. 6, 1329 (2006).

${ }^{14}$ J. Kong, H. T. Soh, A. M. Cassell, C. F. Quate, and H. J. Dai, Nature (London) 395, 878 (1998).

${ }^{15}$ A. Bard and L. R. Faulkner, Electrochemical Methods: Fundamentals and Applications (Wiley, New York, 2001).

${ }^{16}$ S. Heinze, J. Tersoff, R. Martel, V. Derycke, J. Appenzeller, and P. Avouris, Phys. Rev. Lett. 89, 106801 (2002).

${ }^{17}$ A. B. Artyukhin, M. Stadermann, R. W. Friddle, P. Stroeve, O. Bakajin, and A. Noy, Nano Lett. 6, 2080 (2006).

${ }^{18} \mathrm{M}$. Wahlgren, T. Arnebrant, and I. Lundström, J. Colloid Interface Sci. 175, 506 (1995). 